\title{
Regional impacts of ocean color on tropical Pacific variability
}

\author{
W. Anderson, A. Gnanadesikan, and A. Wittenberg \\ NOAA Geophysical Fluid Dynamics Laboratory, Princeton NJ, USA \\ Received: 15 December 2008 - Published in Ocean Sci. Discuss.: 10 February 2009 \\ Revised: 30 July 2009 - Accepted: 5 August 2009 - Published: 20 August 2009
}

\begin{abstract}
The role of the penetration length scale of shortwave radiation into the surface ocean and its impact on tropical Pacific variability is investigated with a fully coupled ocean, atmosphere, land and ice model. Previous work has shown that removal of all ocean color results in a system that tends strongly towards an El Niño state. Results from a suite of surface chlorophyll perturbation experiments show that the mean state and variability of the tropical Pacific is highly sensitive to the concentration and distribution of ocean chlorophyll. Setting the near-oligotrophic regions to contain optically pure water warms the mean state and suppresses variability in the western tropical Pacific. Doing the same above the shadow zones of the tropical Pacific also warms the mean state but enhances the variability. It is shown that increasing penetration can both deepen the pycnocline (which tends to damp El Niño) while shifting the mean circulation so that the wind response to temperature changes is altered. Depending on what region is involved this change in the wind stress can either strengthen or weaken ENSO variability.
\end{abstract}

\section{Introduction}

Due to the presence of phytoplankton pigments, colored dissolved organic matter (CDOM), and scatterers such as plankton, bacteria, viruses and suspended particles, a significant amount of the shortwave radiation hitting the ocean surface is absorbed and scattered at depths considerably shallower than would occur in pure water (Martin, 1985; Morel, 1988; Jerlov, 1976). In open ocean environments the primary players in determining the shortwave penetration depth are chlorophyll and CDOM. Not surprisingly, since visible light inhabits a substantial portion of the shortwave spectrum,

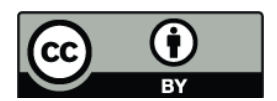

Correspondence to: $\mathrm{W}$. Anderson (whit.anderson@noaa.gov) these constituents are important in determining the characteristic hue of seawater, often termed ocean color. Several bodies of work have investigated or suggested the importance of ocean color on the circulation of the ocean and the climate system (Rosati and Miyakoda, 1988; Lewis et al., 1990; Stramska and Dickey, 1993; Schneider and Zhu, 1998; Nakamoto et al., 2001; Murtugudde et al., 2002; Timmerman and Jin, 2002; Shell et al., 2003; Sweeney et al., 2005; Manizza et al., 2005; Lengaigne et al, 2007). Changes in shortwave absorption have also been found to impact interannual tropical variability, both in hybrid coupled models (Marzeion et al., 2005; Ballabrera-Poy et al., 2007) and fully coupled climate models (Lengaigne et al, 2007; Anderson et al., 2007). This paper extends these results to investigate how changes in ocean color affect ENSO, demonstrating that the response is strongly regionally dependent and involves atmospheric as well as oceanic feedbacks.

The one-dimensional view of the impact of ocean color on solar heating is that as clarity is increased the heating occurs at greater depths (Martin, 1985). Cooler surface temperatures and warmer subsurface waters naturally result. However, ocean-only studies have shown that as water clarity is increased the mean sea surface temperature of the tropical Pacific warms as these warmer deep waters are rapidly upwelled (Nakamoto et al., 2001; Sweeney et al., 2005; Manizza et al., 2005; Anderson et al., 2007) while off-equatorial changes in SST are strongly damped. Interestingly, it appears to be the clarity of waters off equator that play a large role in determining the sea surface temperatures within the Pacific cold tongue. The clarity of these waters sets how much or how little heating is done to subsurface waters that eventually feed into the Equatorial Undercurrent, thus influencing the Pacific cold tongue (Anderson et al., 2007). Also interesting (and possibly troubling), is that these apparently important waters are regions that are relatively clear and in turn are sensitive to "minor" assumptions and details of the optical scheme. 
Coupled experiments show an off-equatorial surface cooling as expected from the one-dimensional response, but show a much larger warming along the equator (Lengaigne et al, 2007; Anderson et al., 2007) than in ocean-only experiments. This is partly due to the weaker damping of SST changes in coupled models versus ocean-only models where the atmospheric temperatures are prescribed (Gnanadesikan and Anderson, 2009). Additionally, coupled models allow SST changes to impact the wind stress fields. Reduction in ocean color leads to warmer sea surface temperatures (SST) in the eastern equatorial Pacific causing the easterly trade winds to slacken and the thermocline to deepen(the so-called "Bjerknes feedback", Bjerknes, 1969). This feedback amplifies the initial equatorial warming induced by the ocean color perturbation (Lengaigne et al, 2007; Anderson et al., 2007). However, as discussed in Gnanadesikan and Anderson (2009) the details of the mean response turn out to be very dependent on the the spatial region where the ocean color is perturbed.

Because changes in shortwave absorption can trigger Bjerknes feedbacks, a number of authors have suggested that they can affect El Niño. In a one-dimensional sense, one might expect high chlorophyll concentrations associated with La Niña to produce more near-surface heating and low chlorophyll concentrations associated with El Niño to produce weaker near-surface heating, so that color would act as a negative feedback on El Niño. However, Marzeion et al. (2005) argued that the indirect effects of this heating in changing the rate of upwelling (as found by Murtugudde et al., 2002 and Sweeney et al., 2005) resulted in enhancing the variability in the volume of light water so that ENSO ended up being enhanced. Several studies using fully coupled climate models have shown that changing oceanic shortwave attenuation rates has an impact on tropical variability (Wetzel et al., 2006; Lengaigne et al, 2007; Anderson et al., 2007). Each study used a different climate model and perturbation strategy. Wetzel et al. (2006) changed the e-folding scale from $11 \mathrm{~m}$ to a spatially varying field and found a reduction in ENSO variability. Lengaigne et al. (2007) examined the difference between using a constant attenuation depth and predicted chlorophyll concentrations. They found an increase in ENSO variability which they argued was related to the mean chlorophyll change- not the variability. Anderson et al., 2007 looked at the differences in using SeaWiFS monthly mean climatology (annual mean shown in Fig. 1a) to set the shortwave attenuation rate and using optically pure water (globally and in predetermined regions), simulating an increase in ENSO variability when a realistic distribution of color was used. Insofar as these papers discussed the mechanisms responsible for the changes in El Niño, they primarily focussed on changes in the mean oceanic temperature structure.

This paper has two main thrusts. First, we extend the discussion of the impacts of ocean color on ENSO to include atmospheric as well as oceanic feedbacks. Second, following the work of Gnanadesikan and Anderson (2009), we show that the character of ENSO response to ocean color

\section{$\log _{10}$ Surface Chlorophyll Concentration $\left(\mathrm{mg} / \mathrm{m}^{3}\right)$}

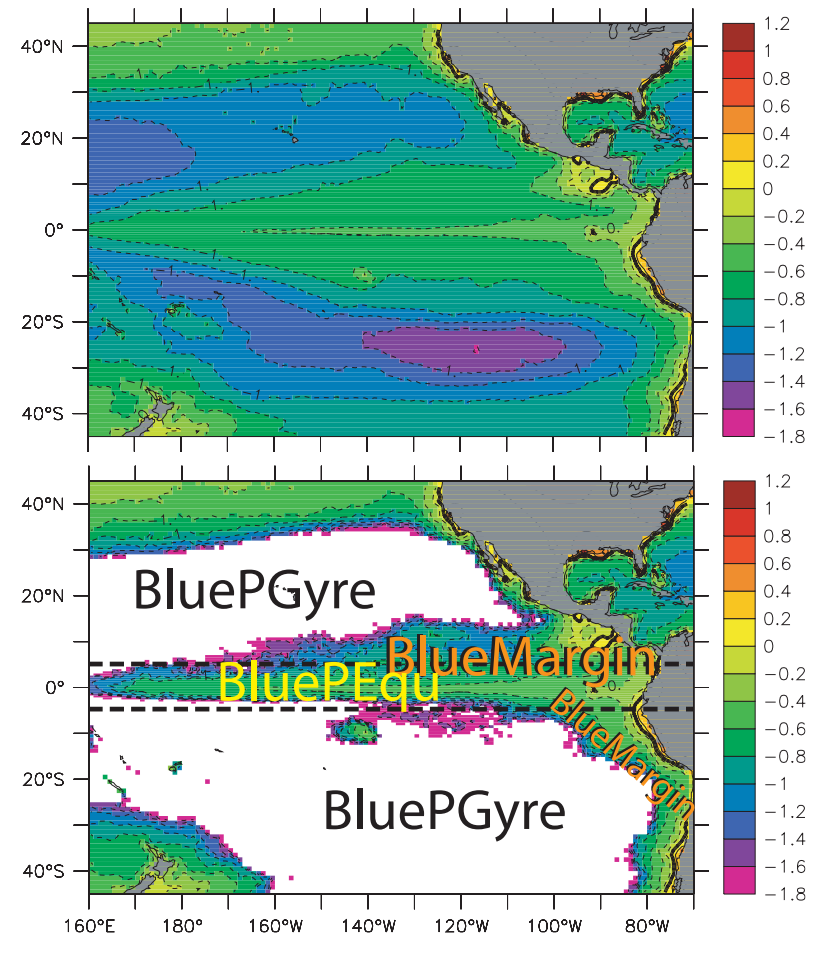

Fig. 1. $\log _{10}$ annual maximum of SeaWiFS surface chlorophyll-a concentrations (upper panel). In the BluePGyre experiment chlorophyll concentrations are set to 0 where concentrations are below $0.2 \mathrm{mg} / \mathrm{m}^{3}$ in the Pacific (white areas lower panel). In BlueMargin, chlorophyll concentrations are set to 0 where concentrations are above $0.2 \mathrm{mg} / \mathrm{m}^{3}$. BluePEqu experiments set chlorophyll concentrations to 0 between $5 \mathrm{~N}$ and $5 \mathrm{~S}$ in the Pacific (denoted by the box in the lower panel). In the Blue experiments chlorophyll concentrations are set to 0 globally.

depends on what region is perturbed. Understanding this regional dependence is motivated in part by recent studies on the variability of ocean water clarity, which show large regional changes. Paleoproductivity estimates (Paytan and Griffith, 2007) suggest that significant (up to a factor of 5) changes in particle export occur in a number of cores implying large changes in chlorophyll concentration at these locations. Karl et al. (2001) suggest that chlorophyll concentrations at station ALOHA could have doubled between the 1950s and the present. Analysis of interannual variability in the SeaWiFS chlorophyll-a retrievals from 1998-2004 (McClain et al., 2004) shows that even over this relatively short period, over $40 \%$ of the ocean the observed temporal range of chlorophyll is more than $40 \%$ of the mean value. A particularly striking feature is the high variability occurring along the boundary between the high and low chlorophyll zones.

The structure of this paper is as follows. In Sect. 2, we present the coupled climate model used in this paper and 
outline the regional perturbations to water clarity that we use to probe the sensitivity of the climate system. Section 3 examines how regional changes in water clarity affect various components of the coupled atmosphere-ocean response. Section 4 concludes this paper.

\section{Methods}

\subsection{Model description}

The ocean model used in this study is the Hallberg Isopycnal Model (HIM: Hallberg, 2005). HIM is run at one degree resolution in latitude and longitude, with meridional resolution equatorward of 30 degrees becoming progressively finer, such that the meridional resolution is $3 / 8$ degree at the equator. The ocean mixed layer is represented with a refined bulk mixed layer model (Hallberg, 2003). The distribution of the fifty target density layers is such that ample vertical resolution is available in the Eastern Equatorial Pacific. For this region, the average thickness of the ten shallowest layers is approximately $6 \mathrm{~m}$. HIM is coupled to the atmosphere, land and ice components used in the GFDL global coupled climate model (Delworth et al., 2006). The atmospheric and land components of the model are identical to those used for the CM2.1 global coupled climate model developed for the Fourth Assessement Report of the Intergovernmental Panel on Climate Change and reported in Delworth et al. (2006). The atmosphere is built around a 24-level, $2 \times 2.5$ degree finite volume core with state-of-the-art representations of radiation, convection, and gravity wave drag. The land model is the LM2 model based on the work of Milly and Shmakin (2002), which fixes land properties such as albedo, surface roughness and stomatal resistance (which controls evapotranspiration) based on currently observed land types. The model has one of the better atmospheric simulations in the AR4 dataset (Reichler and Kim, 2008) and when coupled has been found to exhibit a reasonable simulation of El Niño and its feedbacks for a level-coordinate ocean model (Van Oldenborgh et al., 2005; Wittenberg et al., 2006).

The optical model used for estimation of shortwave penetration/attenuation in the water column is based on the one proposed by Manizza et al. (2005). This model was developed from a renanalysis of the data of Morel (1988) and permits chlorophyll concentrations to go to zero. The scheme parameterizes shortwave extinction in terms of near-surface chlorophyll-a concentration.It is consistent with the Morel (1988) scheme in the low chlorophyll limit of its validity. The Manizza scheme has a deeper clear-water shortwave penetration length-scale than previous algorithms, resulting in shortwave-induced heating at depths well beyond $100 \mathrm{~m}$. This heating becomes significant when integrated over decadal and longer time-scales (Gnanadesikan and Anderson, 2009).
As the near-infrared and red-yellow bands of light have short e-folding depths (less than $5 \mathrm{~m}$ ) and our mixed layer in these runs has a minimum depth of $10 \mathrm{~m}$, these bands are simply treated as a surface flux of heat. The blue-green band (with wavelengths less than $550 \mathrm{~nm}$ ) is allowed to penetrate, following a profile given by

$I(z)=I_{b g} e^{-k_{b g} z}=0.21 I_{0} e^{-k_{b g} z}$

$k_{b g}=0.232+0.064 c h l^{0.674}$

Where $I_{0}$ is the total shortwave radiation absorbed by the ocean (21\% of which is taken to be blue-green) and chl is the concentration of chlorophyll-a in $\mathrm{mg} \mathrm{chl} / \mathrm{m}^{3}$. Thus if the chlorophyll is set to 0 , blue-green light has an e-folding depth of $43 \mathrm{~m}$, while at values of $0.2 \mathrm{mg} \mathrm{chl} / \mathrm{m}^{3}$ the e-folding depth is $20 \mathrm{~m}$. In the base state of the model, the chlorophyll concentrations are taken from the non- El Niño SeaWiFS climatology developed by Sweeney et al. (2005) that is currently distributed with the GFDL ocean codes.

It should be noted that in contrast to parameterizations of solar heating such as Morel and Antoine (1994), the parameterization used here does not specifically account for enhanced absorption associated with the deep chlorophyll maximum. This means that in regions which are already clear, such as the central subtropical gyres, our study will underestimate the total impact of ocean color, as the real ocean will have even more absorption than one would parameterize from using surface chlorophyll, as is done in our control case. This does not change the main thrust of this paper, which focuses on the impacts of regional differences in shortwave absorption.

\subsection{Experimental design}

Five global simulations (summarized in Table 1) are run using the same simulation protocol as the 1990 control runs with the GFDL coupled climate model (Delworth et al., 2006) in which aerosols and greenhouse gasses are held constant. Initial conditions for all coupled simulations are identical and are based on those described in Delworth et al., (2006). These experiments were run for 120 (or more) years, long enough to establish surface biases (Gnanadesikan et al., 2006). The control run (Green) uses the SeaWiFS monthly "climatological" composite chlorophyll-a taken from the years 1998-2004 to determine the shortwave absorption profile. In a second simulation (Blue), chlorophyll-a is set to zero to emulate the absorption profile of optically pure water. This perturbation is quite large and unrealistic. This was done intentionally to set an upper limit on the impact of ocean clarity. The Blue model was run for 300 years. Three additional 120 year runs were made in which the chlorophyll concentration was set to zero in the Pacific within 5 degrees of the equator (BluePEqu), set to zero in the Pacific within 30 degrees of the equator when it was less than $0.2 \mathrm{mg} / \mathrm{m}^{3}$ ( BluePGyre), and set to zero within 30 degrees of 


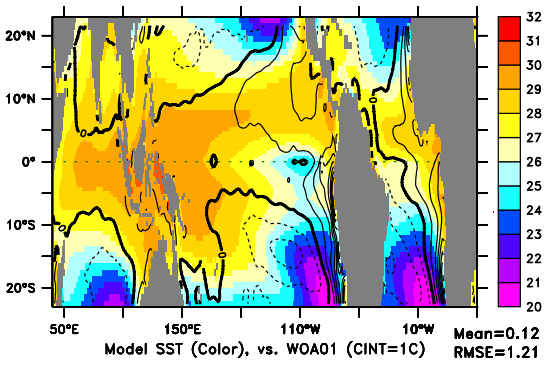

(A) SST and SST Error

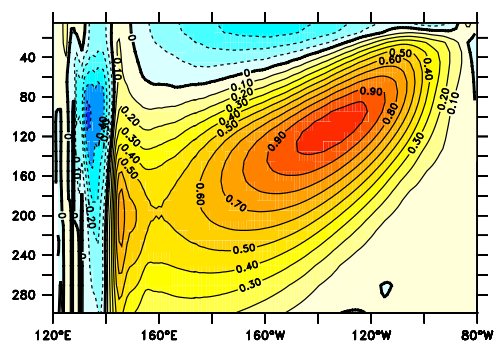

(C) Model $U(\mathrm{~m} / \mathrm{s})$ at Equator

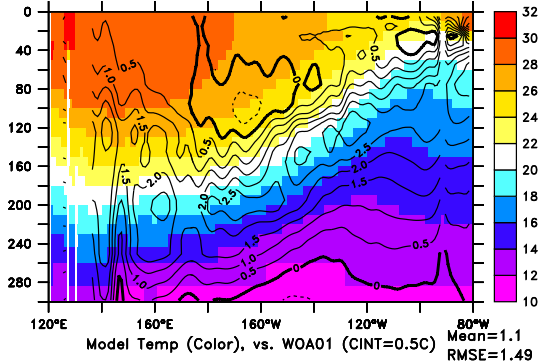

(B) Temp and Temp Error

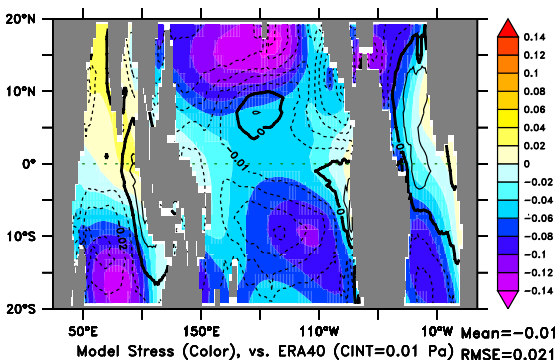

(D) $\tau^{x}(\mathrm{~Pa})$ and $\tau^{\mathbf{x}}$ Error

Fig. 2. Evaluation of model fields that can matter for tropical variability in the Green control model. All fields shown are averages from years 41-120. (A) Model SST (colors) and SST error (contours) relative to WOA01. (B) Model temperature (colors) and temperature error (contours) along the equator in the Pacific sector. (C) Model zonal velocities in the equatorial undercurrent (m/s). (D) Zonal wind stress, in Pascals from the model (colors) and error relative to the ERA40 reanalysis over the time period from 1979-2001.

Table 1. Experiment Summary

\begin{tabular}{ll}
\hline Experiment name & Description \\
\hline Green & Global-monthly chlorophyll climatology based on SeaWIFS \\
Blue & Chlorophyll $=0.0$ everywhere and at all times \\
BluePEqu & Chlorophyll $=0.0,5 \mathrm{~S}-5 \mathrm{~N}$ in the Pacific \\
BluePGyre & Chlorophyll $=0.0$ where $\mathrm{chl}<0.2 \mathrm{mg} / \mathrm{m}^{3}, 30 \mathrm{~S}-30 \mathrm{~N}$ in the Pacific \\
BlueMargin & Chlorophyll $=0.0$ where $\mathrm{chl}>0.2 \mathrm{mg} / \mathrm{m}^{3}, 30 \mathrm{~S}-30 \mathrm{~N}$ \\
\hline
\end{tabular}

the equator globally in regions where the average chlorophyll is greater than 0.2 (BlueMargin). The BluePEqu run can be used to evaluate the impact of equatorial water clarity while the BluePGyre and BlueMargin runs examine the impact of low-productivity, oligotrophic gyre centers versus the higherproductivity, mesotrophic gyre margins that overlie the oxygen minimum zones (Fig. 1b). To avoid initial transients, years 41 to 120 will be used for most of this analysis.

\subsection{Model validation}

As discussed in Gnanadesikan and Anderson (2009) the Green model produces a relatively good mean simulation for a coarse resolution coupled model. The global RMS sea surface temperature error settles down to a value of $1.42^{\circ} \mathrm{C}$ in the third century of the simulation, slightly less than GFDL's CM2.0 model and about $0.2^{\circ} \mathrm{C}$ greater than the
CM2.1 model, with which it shares an atmosphere. Comparing with other models for which the impact of changes in ocean water clarity have been evaluated, the RMS SST error in Green model is slightly worse than the $1.27^{\circ} \mathrm{C}$ in the MPI model of Wetzel et al. (2006), but significantly better than the $1.97^{\circ} \mathrm{C}$ in the IPSL model of Lengaigne et al. (2007). All these models have comparable errors of about $1{ }^{\circ} \mathrm{C}$ in the tropics, though regional patterns differ between them. As shown in Fig. 2a, the Green simulation has relatively small errors in the cold tongue and warm pool, is a little too warm to the north Pacific and too cold to the South Pacific. The largest errors are excessively high temperatures in upwelling regions off the west coast of South America and Africa, a common error in coupled climate models.

The temperature structure (Fig. 2b) along the equator shows a somewhat too-deep penetration of the warm water, so that while $\mathrm{CM} 2.1$ is $0.3^{\circ} \mathrm{C}$ too cold along the 


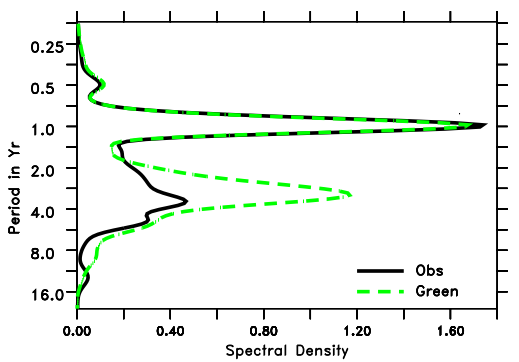

(A) NINO3 SST Spectrum

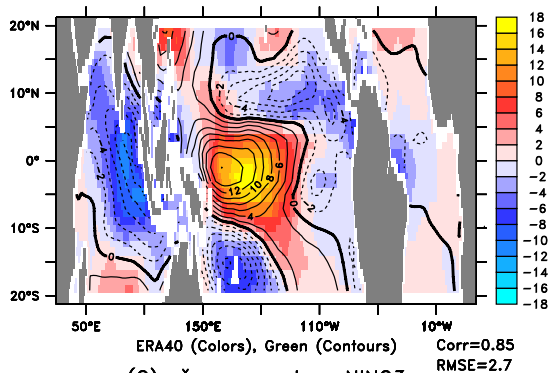

(C) $\tau^{\times}$regressed on $\mathrm{NINO3}$

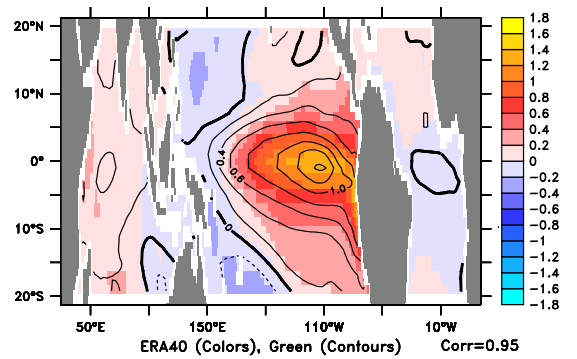

(B) SST regressed on NINO3

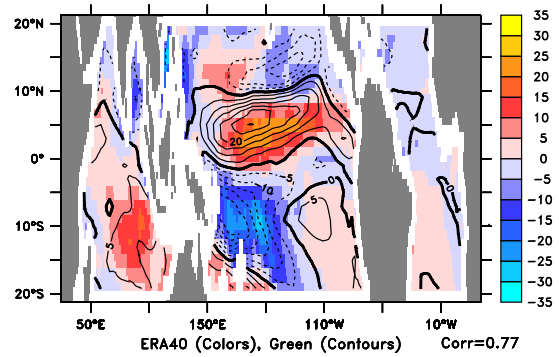

(D) Curl $\tau$ regressed on NINO3 RMSE=5.7

Fig. 3. Evaluation of the tropical variability in the Green control model (years 41-120). (A) NINO3 SST spectrum, NOAA ER.v2 observations (1957-2002, black line) and model (dashed green line). (B) SST regressed on NINO3 SST from ERA40 reanalysis (1979-2001, colors) and the model (contours). (C) Zonal wind stress ( $\mathrm{mPa}$ ) regressed on NINO3 SST from ERA40 reanalysis (colors) and model (contours). (D) Wind stress curl $(\mathrm{mPa} / 1000 \mathrm{~km})$ regressed on NINO3 SST from ERA40 reanalysis (colors) and model (contours).

equator above $250 \mathrm{~m}$ relative to the World Ocean Atlas 2001 (Conkright et al., 2002), the Green run is too warm by $1.2^{\circ} \mathrm{C}$. In general the spatial pattern of the temperature error in the upper $150 \mathrm{~m}$ is quite similar to those in CM2.1- the primary difference is the temperature offset. This is a common error in coupled climate models (Davey et al., 2002). It is possible that this bias reflects some process that is too efficient at moving heat downwards in the water column and therefore may make our model somewhat too sensitive to shortwave penetration. Preliminary evidence suggests that the culprit is too much shear mixing in the undercurrent. Despite the bias in temperature, the equatorial undercurrent (Figure 2c) is relatively realistic (compare with Fig. 8 from Wittenberg et al., 2006) with a maximum of the right magnitude and in the right location. The westward surface current is stronger in this model than in CM2.1, a bias arising from excessively strong westward currents in August and September. This may in part be due to the fact that the zonal wind stress (Fig. 2d) is in general more easterly along the equator (and in general throughout the tropics) than the ERA40 wind stress. Although the wind stress along the equator in the model is only $-0.034 \mathrm{~Pa}$, this is still $20 \%$ larger than the ERA40 wind stress. The easterlies also extend somewhat farther to the west along the equator than in the ERA40 analysis. Both our wind stress and temperature errors are small compared with the models studied in the STOIC project, comparable to the best flux-adjusted models (Davey et al., 2002).
The Green simulation also produces an El Niño that captures many of the important features of the observed phenomenon. As shown in Fig. 3a, the spectrum of SST variability in the NINO3 region shows peaks at the appropriate frequencies, with an annual cycle of about the right magnitude and an El Niño that is too large. RMS variability in the interannual band is $0.97^{\circ} \mathrm{C}$ which is actually smaller than the $1.09^{\circ}$ in a comparable coupled model with a levelcoordinate ocean (Wittenberg et al., 2006), though the frequency is somewhat more peaked. The spatial structure of the SST anomalies (Fig. 3b) is quite close to that in the data, with an overall correlation of 0.95 and RMS errors of $0.13^{\circ} \mathrm{C}$. The modeled SST perturbation extends somewhat too far to the west. The zonal spatial structure of the wind stress anomalies (Fig. 3c) is a bit less well correlated (0.81), as the maximum easterly anomaly is shifted slightly to the northwest compared with the reanalysis and the wind stress curl (Fig. 3d) shows even more of an offset. Nonetheless, the model captures the overall structure of the wind stress anomalies, with the boundaries between different-signed anomalies being well described and the peak magnitude of the anomalies also being well characterized. 


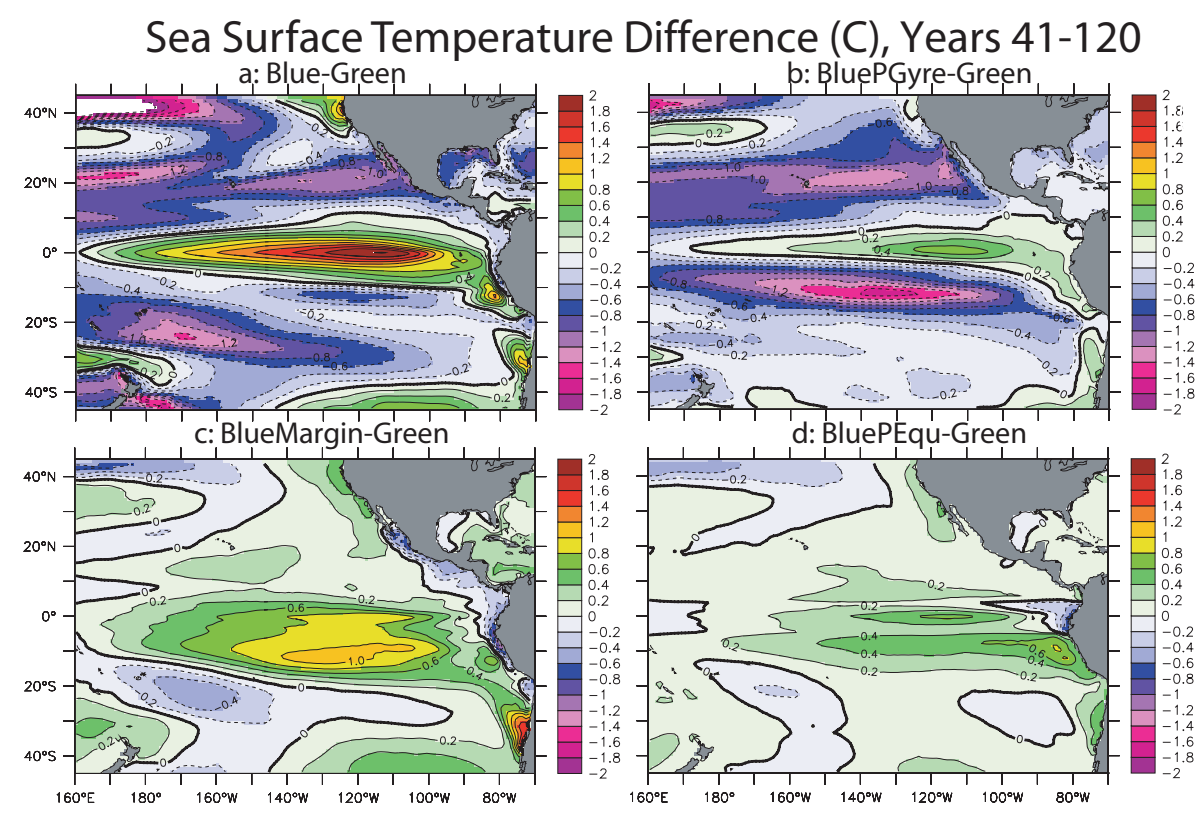

Fig. 4. Mean sea surface temperature differences. (a): Mean difference (years 41-120) for Blue (zero chlorophyll) minus Green (SeaWiFS chlorophyll). (b): Mean difference for BluePGyre (chlorophyll concentrationsbelow $0.2 \mathrm{mg} / \mathrm{m}^{3}$ set to zero in Pacific between latitudes of $30^{\circ} \mathrm{N}$ and S.) minus Green. (c): BlueMargin (chlorophyll concentrations above $0.2 \mathrm{mg} / \mathrm{m}^{3}$ set to zero between latitudes of $30^{\circ} \mathrm{N}$ and S.) minus Green. Bottom (d): BluePEqu (chlorophyll set to zero between $5^{\circ} \mathrm{N}-5^{\circ} \mathrm{S}$ ) in Pacific) minus Green.

\section{Results and discussion}

\subsection{Mean state changes}

That ocean water clarity has an important impact on sea surface temperature and wind stress is clearly shown in Fig. 4. Removing chlorophyll everywhere (Blue-Green, Fig. 4a) results in a strong warming in the central Pacific, with cooling off-equator in the subtropical gyres. As discussed in Gnanadesikan and Anderson (2009) there is also strong cooling in the Atlantic subtropical gyres and at the boundary between the subtropical and subpolar gyres. There is strong warming in the subpolar gyres. The BluePGyre run shows a signal of strong cooling just off-equator, but with a weaker warming along the equator (Fig. 4b). The BlueMargin run shows a strong warming in Eastern Equatorial Pacific, but very little cooling off-equator. Interestingly, the BluePEqu run displayed the weakest response (as discussed in Anderson et al., 2007) emphasizing the relatively weak role of equatorial chlorophyll in determining equatorial climate. Further details on the mean state changes can be found in Gnanadesikan and Anderson (2009).

The atmospheric circulation changes associated with these SST changes have a complicated but understandable pattern. The warming in the East Pacific associated with the BlueMargin run results in a roughly $15 \%$ decrease in the Walker circulation (Fig. 5a). The off-equatorial cooling associated with the BluePGyre runs causes an increase in equatorward

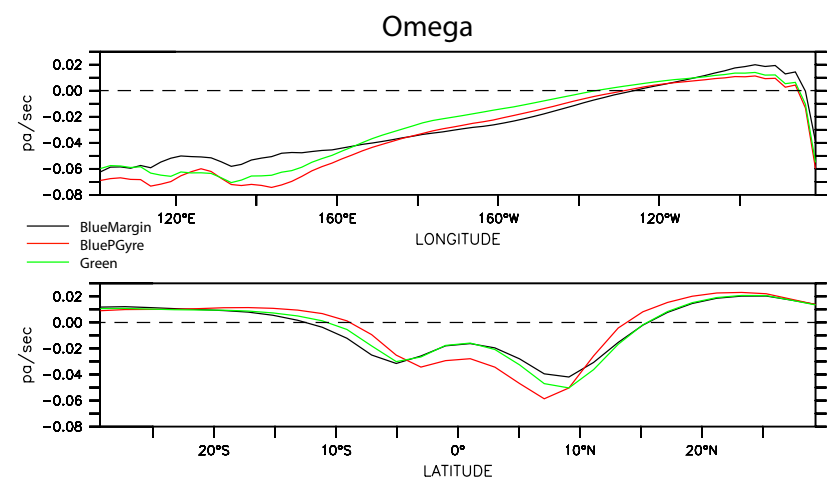

Fig. 5. Omega $\left(\mathrm{Pa}^{-1}\right)$ at $500 \mathrm{mb}$, years 41-120. The upper panel spans $110^{\circ} \mathrm{E}$ to $100^{\circ} \mathrm{W}$ and is averaged from $10^{\circ} \mathrm{S}$ to $10^{\circ} \mathrm{N}$. The lower panel spans $30^{\circ} \mathrm{S}$ to $30^{\circ} \mathrm{N}$ and is averaged from $110^{\circ} \mathrm{E}$ to $100^{\circ} \mathrm{W}$. Note the relaxation of the Walker circulation in BlueMargin (black line) and the intensification and narrowing of the Hadley circulation in BluePGyre (red line) relative to Green (green line).

winds to the north and south of the equator in the central Pacific, associated with an increase in but also a narrowing of the Hadley circulation (Fig. 5b). The Blue run shows a combination of these two changes. 


\section{Mean Spectra, Nino3 SST years 41-120}

first/last/mid/all epochs
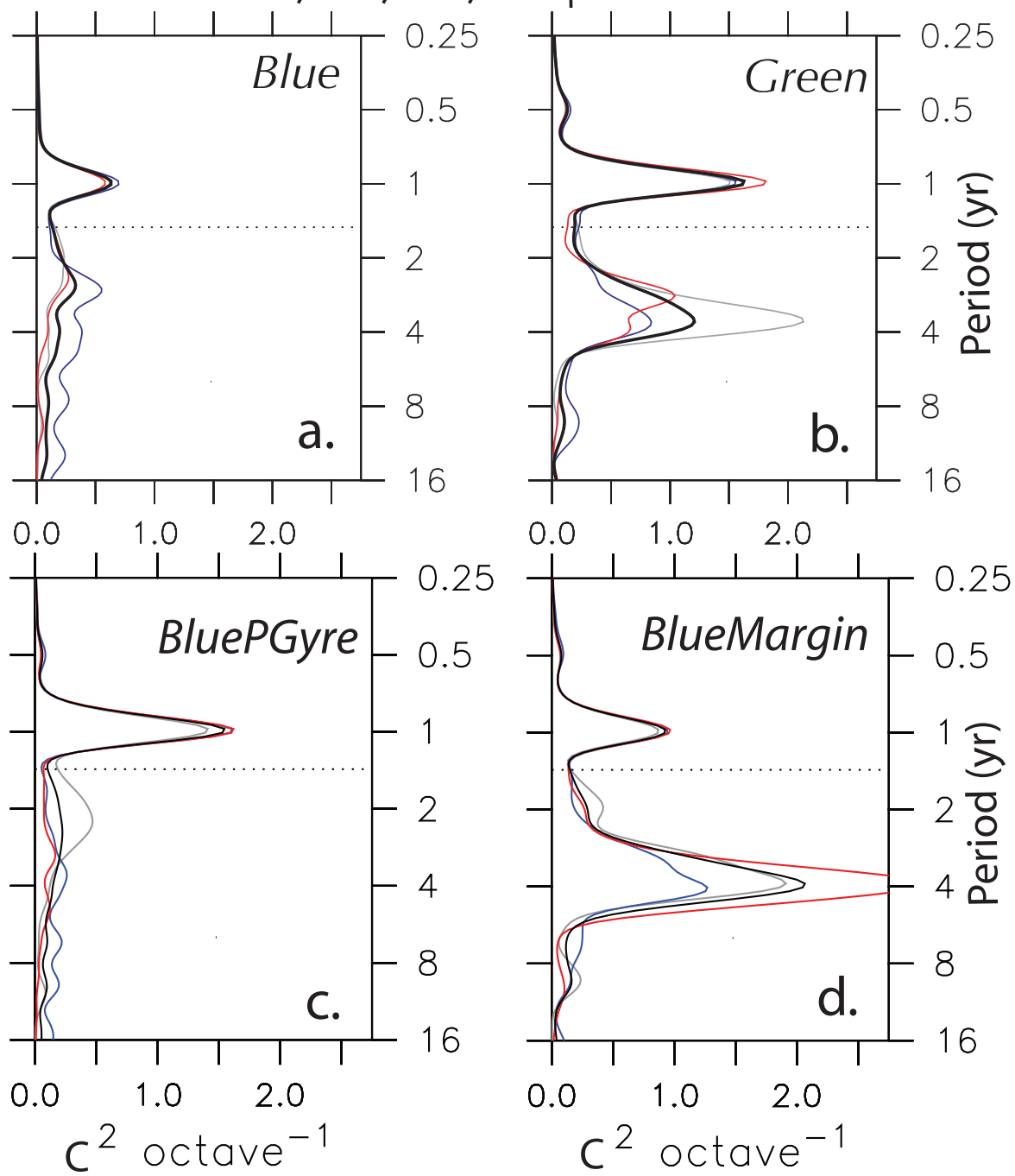

Fig. 6. Mean spectra analysis for NINO3 SST, (years 41-120) Dark black line shows the mean for the entire period, blue, red and gray lines show the spectra for the first, last, and middle third of the period, respectively, providing a sense of the interdecadal variability in NINO3 spectra. The Blue run (a) has little power in the annual or ENSO spectral bands when compared to the Green run (b). BluePGyre (c) has a similar spectrum the ENSO band as Blue, but a similar power in the annual band as Green. BlueMargin (d) alone has an increase of power in ENSO bands and a decrease in power in the annual bands.

\subsection{Tropical variability}

Tropical variability in the coupled model is sensitive to the regional distribution of ocean color (Fig. 6). The Blue run (Fig. 6a) has little power in the annual or ENSO spectral bands when compared to the Green run (Fig. 6b). BluePGyre (Fig. 6c) has a similar spectrum the ENSO band as Blue. BlueMargin (Fig. 6d) alone has an increase of power in ENSO bands. BluePEqu (not shown) had spectral characteristics very similar to Green, though with a somewhat weaker annual cycle. In this paper we focus on the mechanisms leading to changes in the ENSO band.

Previous studies have shown that changes in ocean color can have an impact on tropical variability (Murtugudde et al., 2002; Wetzel et al., 2006; Lengaigne et al, 2007). In explaining this impact these studies have focused on the mean state of the Pacific tropical thermocline. Their arguments follow the work of Federov et al. (2006) in that there are two main processes controlling tropical Pacific variability. One is an adiabatic redistribution of warm water which drives changes 
Table 2. Correlation and regression coefficients for anomalous air-sea heat fluxes and anomalous SST over the NINO3 region. Negative values mean that anomalies are damped. Regression coefficients are in units of $\mathrm{W} / \mathrm{m}^{2} / \mathrm{C}$. Total air-sea heat flux is shown in columns 2 and 3 , shortwave only in columns 4 and 5.

\begin{tabular}{lcccr}
\hline & Heat flux-SST & \multicolumn{3}{c}{ Shortwave-SST } \\
\hline Green & Correlation & Regression & Correlation & Regression \\
Blue & -0.91 & -11 & -0.58 & -2.8 \\
BluePEqu & -0.89 & -21 & -0.85 & -13 \\
BluePGyre & -0.74 & -13 & -0.67 & -4.3 \\
BlueMargin & -0.79 & -12 & -0.58 & -4.8 \\
\hline
\end{tabular}

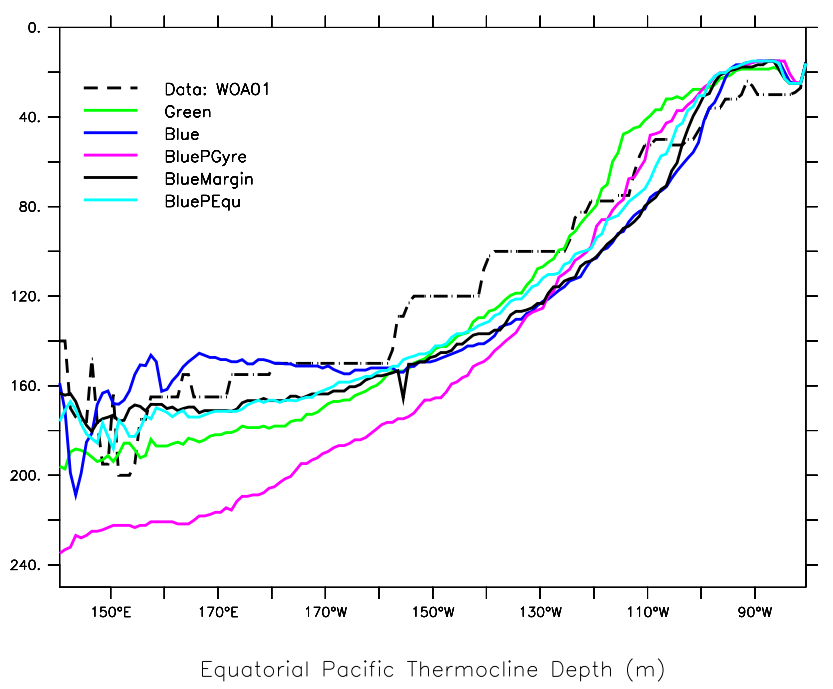

Fig. 7. Mean thermocline depths for the region $2^{\circ} \mathrm{S}-2^{\circ} \mathrm{N} 200^{\circ} \mathrm{W}-$ $80^{\circ} \mathrm{W}$. Thermocline is defined as the depth at which the maximum vertical gradient is found. Data is taken from World Ocean Atlas 2001 (Conkright et al., 2002). Note that all the runs have a deeper thermocline than Green in the Eastern Pacific, regardless of whether the El Niño is stronger or weaker.

in the mean equatorial thermocline slope. This change in slope characterizes the interannual El Niño Southern Oscillation. Longer term variations in variability are driven by slow diabatic changes in the warm upper waters which lead to vertical migration of the thermocline over the whole tropics. If the thermocline is driven deep enough it is theorized that this could lead to a permanent or persistent warm event.

Examining the mean thermocline depth in these experiments leads us to believe that there are other drivers of the change in variability (Fig. 7). Looking from the central to the eastern Pacific, the deepest mean thermocline is found in Blue (with little ENSO variability) followed by BlueMargin (which has the most variability in the ENSO band). Green and BluePEqu (with reasonable levels of ENSO variability) and BluePGyre (with little ENSO variability) have similar thermocline depths and slopes east of the date line. The

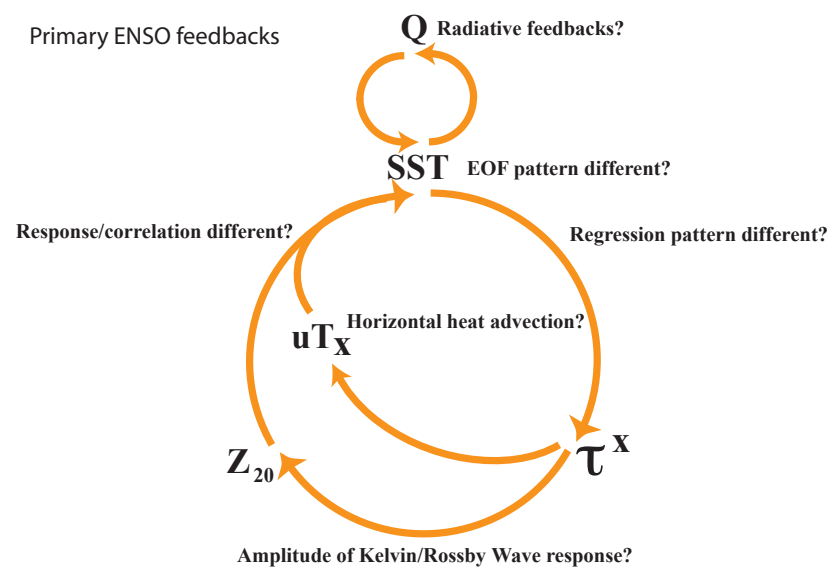

Fig. 8. Cartoon depicting the major feedback loops in the ENSO system.

changes in Pacific tropical variability must not be solely due to changes in slope and mean depth of the mean thermocline. This result is consistent with the work of Song et al. (2007) who found a deeper pycnocline but stronger El Niño associated with closing the Indonesian throughflow. It is also consistent with Philip and van Oldenborgh (2006) who found in a range of global coupled climate models that a shallowing of the thermocline under global warming was significantly compensated by higher thermal damping and a more stable atmosphere, so that the net change in ENSO amplitude was small.

To investigate other possible mechanisms for changes in the variability we focused on the primary ENSO feedbacks (Fig. 8).Could we explain the variability differences as a function of the differences in atmospheric thermodynamic feedbacks? Do changes in variability result from differences in the spatial pattern of SST variations (Van Oldenborgh et al., 2005)? Are the changes in variability due to varying atmospheric states that respond differently to SST anomalies? Are the changes due to oceanic mean state changes that lead to varying thermocline and surface current adjustment/response to wind anomalies? Or are the changes in 


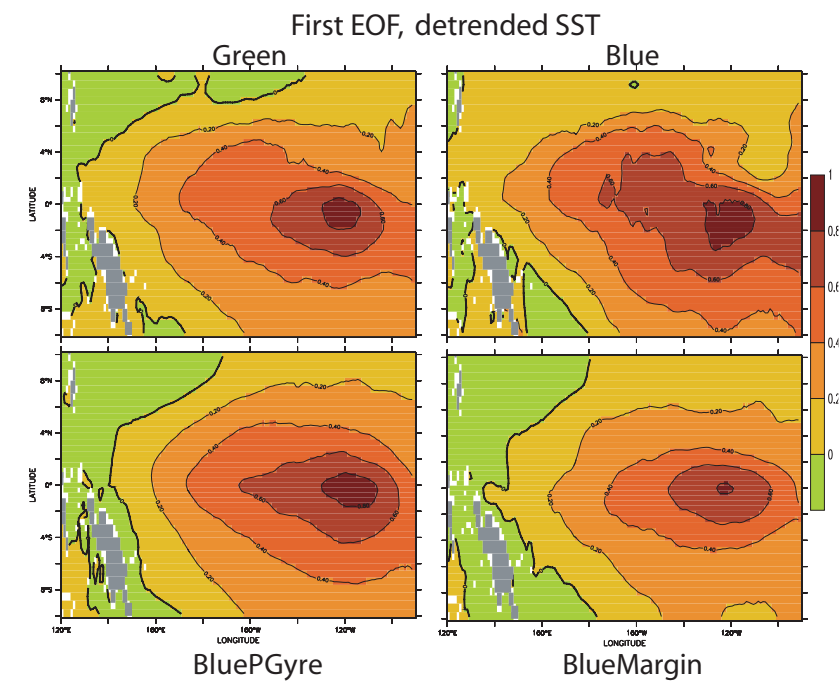

Fig. 9. First empirical orthogonal function (EOF) for the detrended SST (normalized to unit amplitude). Green (upper left), Blue (upper right) BluePGyre (lower left) and BlueMargin (lower right). Although there are differences between the EOFs (note differences between top and bottom rows), they do not map onto differences in ENSO amplitude (left column has strong ENSO, right column weak ENSO).

variability due to differences in how subsurface changes in temperature make their way to the surface via upwelling and mixing?

In Table 2 we investigate the possibility that the variability differences seen are due to differences in heat flux feedbacks. We do this by examining correlation and regression coefficients between heat flux and SST (left) and shortwave flux and SST (right). Looking at the Heat flux-SST section we see that the correlation strengths are relatively similar. In the regression column the only marked change in strength is shown in a substantial increase in the Blue (consistent with a weaker ENSO) and some strengthening in the BlueMargin simulation (inconsistent with a stronger ENSO). In line with the Heat flux-SST section, the Shortwave-SST section shows a large jump in regression strength in the Blue and a slight strengthening in the BlueMargin simulation. This is because the convection shifts to the east in both simulations, resulting in more cloud shading when El Niño results in a further shift of convection to the east. While the heat flux feedback is consistent with the difference between Blue and Green, the results of this analysis do not explain why the other runs differ. Surface heat flux feedbacks alone do not seem to explain the variability differences.

Next we look at how ENSO manifests itself in SST perturbations among the various experiments. Figure 9 shows the first empirical orthogonal function (EOF) for the detrended SST (normalized to unit amplitude) for the region $10^{\circ} \mathrm{S}-$ $10^{\circ} \mathrm{N}, 120^{\circ} \mathrm{E}-90^{\circ} \mathrm{W}$. This EOF will contain the main pat- tern of inter-annual variability and allow us to compare the ENSO expression between experiments. At first glance there appear to be subtle differences, less than what is seen in intermodel comparisons where the models are configured as similarly as possible (Van Oldenborgh et al., 2005). Nevertheless, the centers of action and the regions containing the bulk of the variability are relatively consistent between experiments and the overall character of the ENSOs appear the same. Insofar as there are differences in the slope of the temperature anomaly from northwest to southeast, the Blue and Green models (Fig. 9 top row) contrast with the BlueMargin and BluePGyre models (Fig. 9 bottom row) so that each row has a model with one strong and one weak ENSO. The changes in variability do not appear to be a result in a change in SST spatial pattern.

The next mechanism for variability change explored is in wind response to these SST patterns. Shown in Figure 10 is the $10 \mathrm{~m}$ wind speed regression versus NINO3 $\left(5^{\circ} \mathrm{S}-5^{\circ} \mathrm{N}, 150^{\circ} \mathrm{W}-90^{\circ} \mathrm{W}\right) \mathrm{SST}$ anomalies. The left column is for September-October-November (SON). The right is for December-January-Febuary (DJF). Here we see a response that is consistent with the changes in variability. The experiments with strong ENSOs (BlueMargin, Green and BluePEqu) have a wind response with a longer fetch than those with weak ENSOs (Blue and BluePGyre). What is likely being seen here is a response to the changes in the strengths of the Walker and Hadley circulations in the various experiments (Fig. 5). When the Hadley cell is very strong (as in BluePGyre and Blue) and the convergence is centered over Indonesia it becomes very difficult for changes in SST to move the convergence and winds out over the Pacific. When the Walker cell is weak (as in BlueMargin) it is easier for the atmosphere to respond to changes in NINO3 SST.

The regression analyses suggest that there is a connection between the wind response, SST anomalies and tropical variability. The question is, how much of this can be explained by atmospheric and/or oceanic mean states? To address this question two suites of ocean-only experiments were engineered. In one suite (Different Winds, Same Ocean) the 100 year mean state of the Green ocean is used to initialize all members. A control run is made using the 100-year climatological winds from the Green run and perturbations are made using the wind perturbations shown in Figure 10. This suite thus examines how much of the difference in the oceanic response is due to the differences in the structure of the wind stress perturbation. In the other suite (Different Ocean, Same Winds) the oceans are initialized with the 100 year mean states from the various coupled experiments. For each ocean, a control run is made using winds from the 100 year mean monthly climatology from the Green experiment and an El Niño run was made using the wind perturbation from the Green experiment. This suite thus shows the impact of the ocean changes on ocean response. 


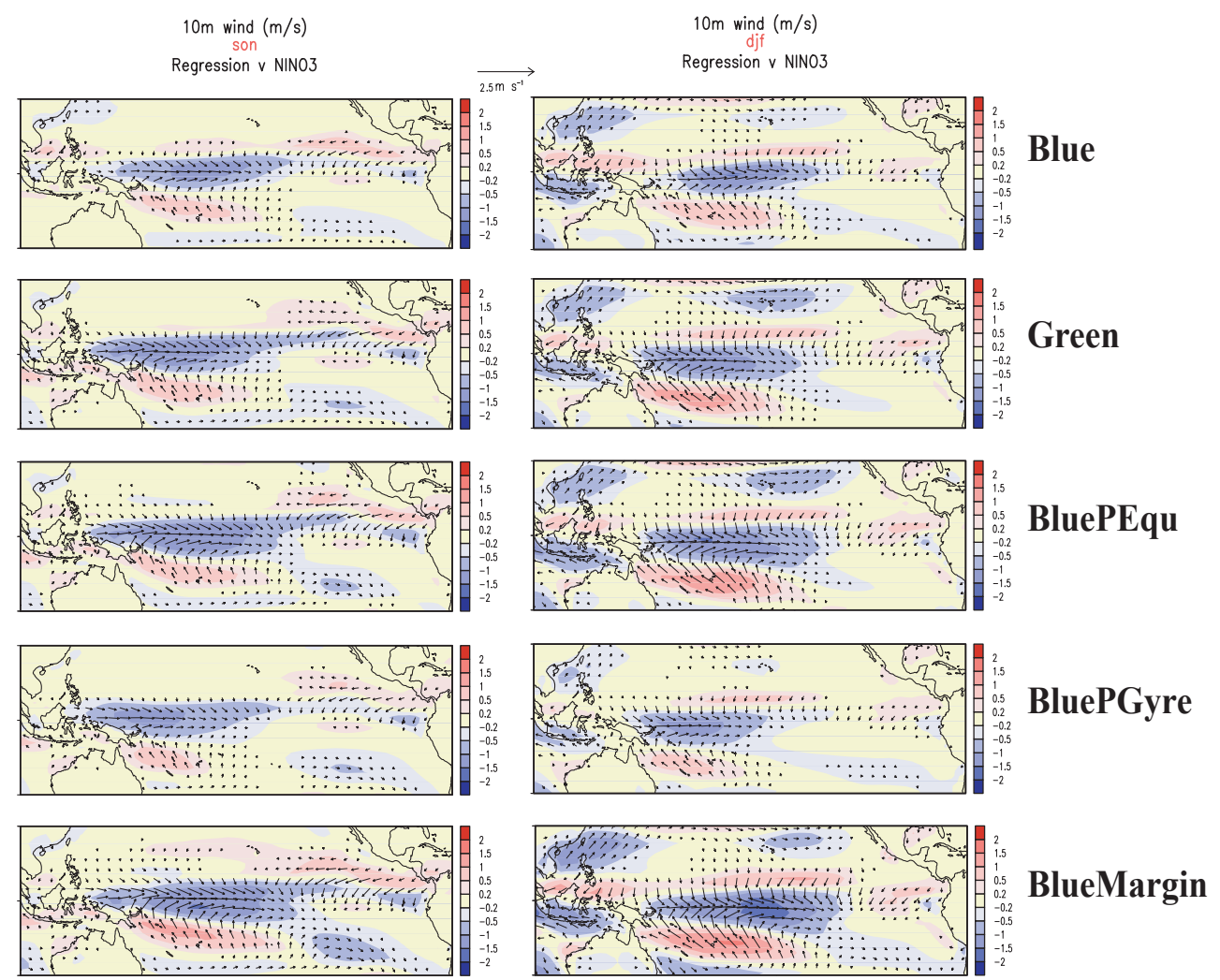

Fig. 10. $10 \mathrm{~m}$ wind speed regression versus NINO3 $\left(5^{\circ} \mathrm{S}-5^{\circ} \mathrm{N}, 150^{\circ} \mathrm{W}-90^{\circ} \mathrm{W}\right) \mathrm{SST}$ anomalies for the different experiments. The left column is September-October-November (SON). The right is December-January-Febuary (DJF). Rows (top to bottom) are for Blue, Green, BluePEqu, BluePGyre and BlueMargin, respectively. Note that Blue and BluePGyre simulations (with weak ENSOs) show smaller regions of wind change than the BlueMargin, Green, and BluePEqu (with stronger ENSOs).

The members of the two suites were each run out for one year, and the differences between the states forced by El Niño winds and those forced by control winds are presented. Figure 11 shows the response of heat content and the temperature profile for two suites of ocean-only experiments. The results from this suite highlight the different impact of the wind stresses as shown in the regression analysis. This is most clearly seen in the top row of Fig. 11 (Same Ocean, Different Winds) with the enhanced response for BlueMargin and smaller response for BluePGyre. However, the BluePEqu El Niño winds produce a stronger response than the Green runs, while the Blue El Niño winds produce a response that is only slightly weaker. The bottom row of Fig. 11 (Different Ocean, Same Winds) suggest that changes in the ocean state are critical in explaining the diminished response in the Blue run, with much lower heat content and temperature response than in Green. The changes in ocean state also act to reinforce the weaker El Niño in the BluePGyre run. The BluePEqu ocean also shows a weaker response to El Niño wind perturbations than the Green ocean. The Same Ocean, Different winds suite demonstrates that the Federov et al. (2006) mechanism is in play in all of our runs, even BlueMargin, but that in this final run it is overwhelmed by the change in wind stress. Evidently, mean state changes in both the atmosphere and the ocean play a role in setting up tropical variability.

The ocean-only suites assume that atmospheric temperatures and humidities remain unchanged under ENSO. They will thus underestimate the impact of near-surface changes in advective temperature tendencies, which have been suggested to play an important role in modulating ENSO (Picaut et al., 1996; Burgers and van Oldenborgh, 2003; Guilyardi, 2006). To examine whether such changes play a role in explaining the differences between the modeled ENSO cycles we performed a lagged regession of $u^{\prime} \bar{T}_{x}$ with respect to NINO3 SST anomaly as a function of longitude, shown in Fig. 12. Lags are computed with respect to the temperature field. In this framework a positive value at zero lag would mean that advection was causing temperature anomalies to amplify, and would thus be a destabilizing influence. Positive values at negative lags mean that the zonal advection leads the temperature peak and thus that advective heat flux accelerates transitions between states (Wittenberg, 2002). This is what is generally seen in Fig. 12. Additionally, the magnitude of the advective heat flux response is actually a quite 

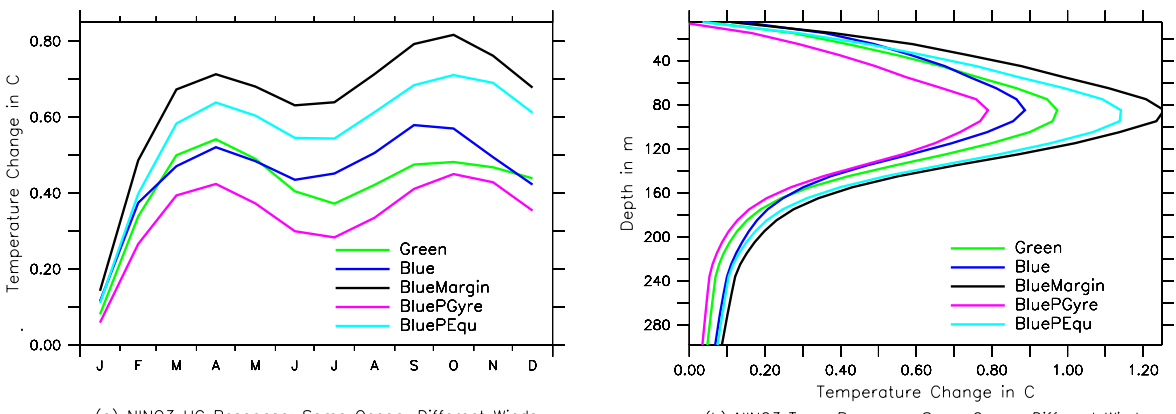

(a) NINO3 HC Response: Some Oceon, Different Winds
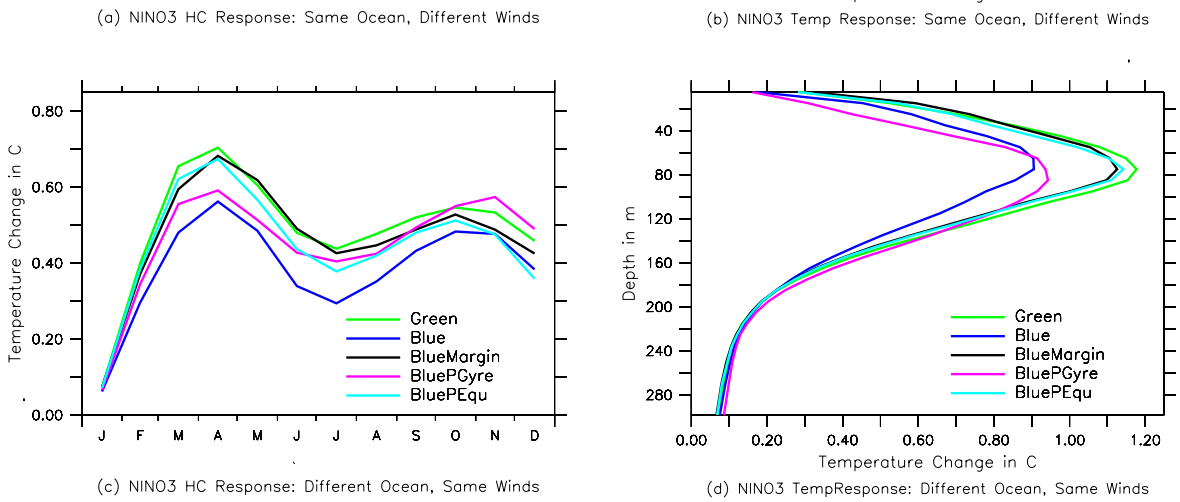

Fig. 11. The response of heat content and the temperature profile for two suites of ocean-only experiments. In one suite (Different Winds, Same Ocean, top row) the 100 year mean state of the Green ocean is used to initialize all members and the winds driving the members are the 100 year monthly mean Green climatology and 100 year monthly mean Green climatology + El Niño winds for the various coupled runs. In the other suite (Different Ocean, Same Winds, bottom row) the oceans are initialized with the 100 year mean states from the various coupled experiments and the atmosphere is the 100 year monthly mean Green climatology and the 100 year mean monthly Green climatology $+\mathrm{El}$ Niño winds from the Green run. The left hand side shows the difference in heat content over the top $200 \mathrm{~m}$ between the control and El Niño runs. The right-hand side shows the profile of the temperature difference between control and El Niño runs in April, when the heat content difference is at its maximum. Note that for the same ocean (top row) the BlueMargin with the strongest El Niño shows the strongest response, and the BluePGyre with the weakest El Niño shows the weakest response, but differences between the Blue and Green runs are less clear. For the different oceans, but the same winds (bottom row) the Blue run has a much weaker response than the Green run.

poor predictor of whether ENSO will be strong or weak. One of the weak ENSO cases (Blue) has a relatively strong advective response at zero lag, while the other weak ENSO case (BluePGyre) has a relatively weak response. The strongest ENSO (BlueMargin) lies in between these two cases at zero lag, though its response is much more spread out over time. It should be noted that the advective temperature tendencies do show different temporal behavior, with the highly periodic BlueMargin simulation showing correlations over longer periods of time. We believe that this mechanism is potentially important for explaining differences in the frequency spectrum between the models, but a detailed analysis of this is beyond the scope of this paper.

The last of the avenues we explore in this study is the communication between the subsurface and the surface of the ocean. Regressions and correlations between the sea surface temperature and the temperatures in upper $300 \mathrm{~m}$ (Fig. 13) show a very similar pattern between between BlueMargin (strongest ENSO) and BluePGyre (weakest ENSO). Although there are some differences in the response at the base of the mixed layer in the eastern equatorial Pacific,these actually go in the wrong direction (if one supposes that the temperature change propagates up from below, a larger subsurface temperature change is needed to give a 1C SST increase in the BlueMargin run with a stronger El Niño). This suggests that differences in the connection between subsurface temperatures and surface temperatures are not primarily responsible for the differences in ENSO amplitude. Further evidence is provided in Fig. 14, which shows the time lagged regressions between subsurface temperature in the NINO3 region and the NINO3 SST, with negative lags showing the subsurface temperatures leading the SST. Subsurface temperatures were averaged over depths of 50-100 $\mathrm{m}$, but the results are largely insensitive to the exact choice of depths. At lead times of a few months, the relative differences between the models are very small. At such short lead times, the subsurface anomalies in the Blue and BlueMargin runs with weak ENSOs bracket the BlueMargin, BluePEqu and Green runs with stronger ENSOs. As we would in general expect a weaker ENSO to require higher deep temperature 

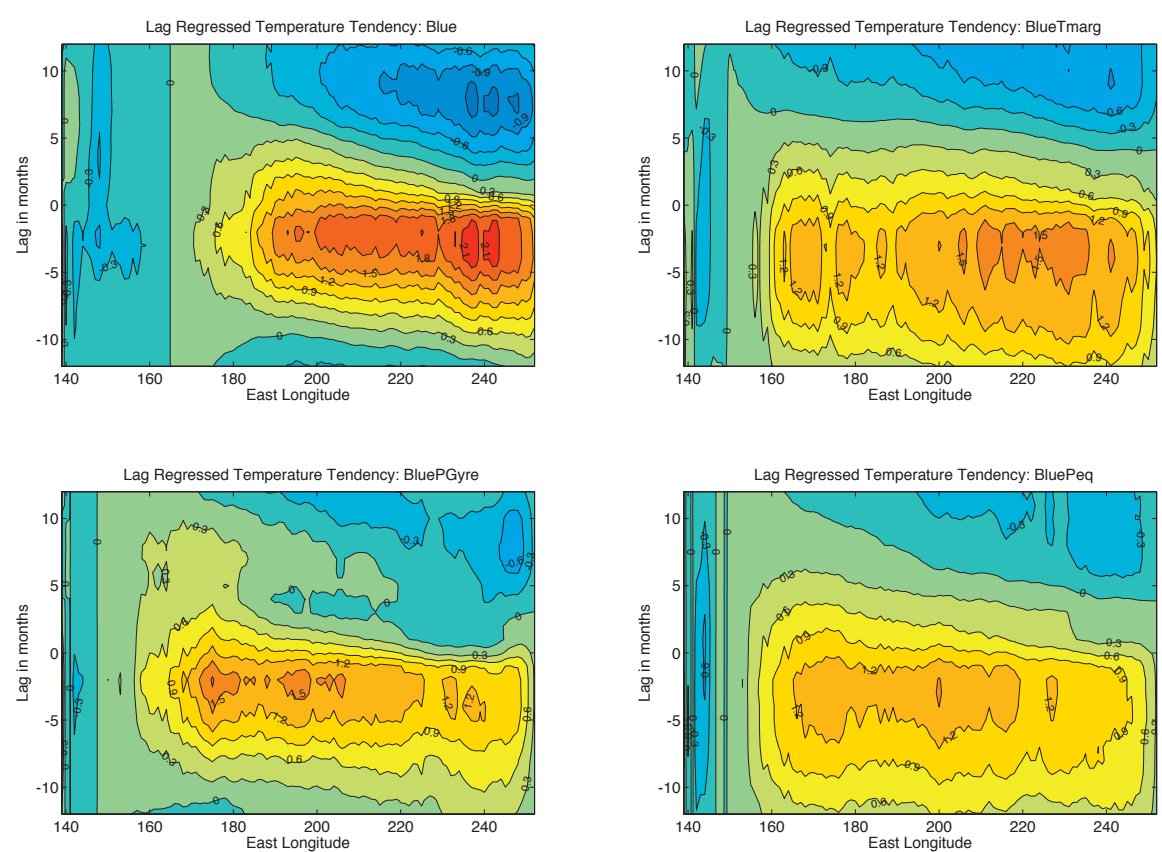

Fig. 12. Lagged regression of NINO3 temperature anomaly with anomalous zonal advective heating tendency $u^{\prime} T_{x}$. Positive lags mean temperature lags heating tendency, negative lags mean temperature leads heating tendency. Contours are $0.3 \mathrm{C} / \mathrm{yr}$. Upper left: Blue run (weak ENSO). Upper right: BlueMargin run (strongest ENSO). Lower left: BluePGyre run (weak ENSO). Lower right: BluePEq run (normal ENSO).

anomalies, this signal does not seem to be the primary driver of the changes in ENSO amplitude even when time variability is included.

At larger lags, the BlueMargin run does show much more long-term temporal autocorrelation between subsurface anomalies and the NINO3 SST. We believe this to be the result of stronger air-sea coupling. As illustrated in Fig. 11, over 4 months, a $1^{\circ} \mathrm{C}$ NINO3 SST anomaly in BlueMargin produces winds that drive a $1.2^{\circ} \mathrm{C}$ subsurface temperature perturbation, which is enough to maintain the surface temperature anomaly,. The BlueMargin case is thus potentially self-sustaining given weak enough heat flux damping. By contrast, the Blue and BlueMargin cases produce subsurface temperature anomalies that are much weaker, both because the wind stress response is weaker (Fig. 11, upper right) and because the subsurface ocean has less of a response (Fig. 11, lower right). Such cases are thus weakly damped, cannot sustain an oscillation, and thus have much weaker long term temporal autocorrelation.

\section{Conclusions}

We have demonstrated that the ocean color has not only an impact on tropical mean state but on tropical variability as well. We show that this response is regionally dependent and mediated by mechanisms involving both the atmosphere and the ocean. A summary of how these mechanisms map onto the various runs is presented in Figure 15. The Blue run yields a weaker ENSO because of a combination of stronger heat flux damping and and weaker oceanic response to wind stress forcing. The BlueMargin run yields a stronger ENSO primarily because the atmospheric response to changes in SST is stronger as mean warming in the Eastern Equatorial Pacific moves the convection eastward. The BluePEqu run also shows this response in the wind stress, but it is compensated by the weaker oceanic response as in the Blue simulation. The BluePGyre run has the weakest ENSO as a shorter fetch and weaker oceanic response to wind stress perturbations work in the same direction.

It has been shown that mean state changes (in the atmosphere as well as ocean) resulting from changes in ocean color play a role setting up tropical variability. These results suggest a number of future avenues of investigation. One of these relates to impacts of the ocean color on the annual cycle of temperature, which we have neglected in this work for reasons of conciseness. Preliminary analysis suggests that as with ENSO, the magnitude and pattern of the changes in the annual cycle are not due to one component alone. In some parts of the near-equatorial Pacific changes in the meridional wind stress appear to be most important, while in nearby regions, large differences in the oceanic stratification between simulations appear to be the source of the differences. Second, when looking at ENSO variability and 


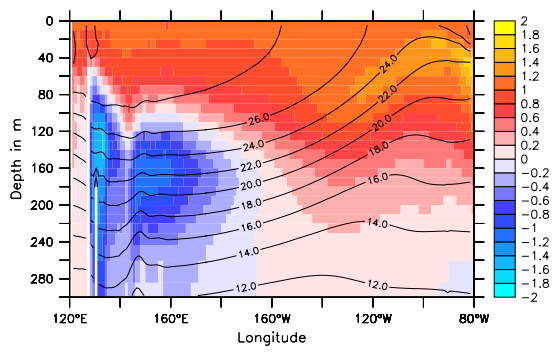

(a) SST-Temperature Regression: BlueMargin

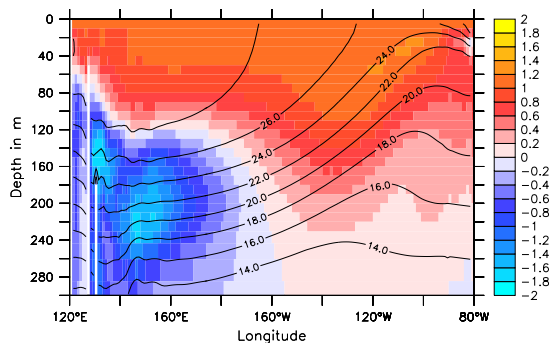

(c) SST-Temperoture Regression: BluePGyre

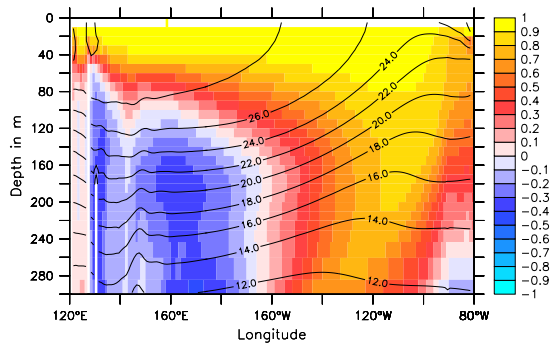

(b) SST-Temperature:Correlation: BlueMargin

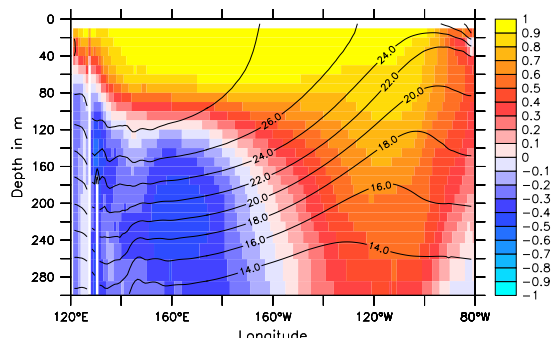

(d) SST-Temperature:Correlation: BluePGyre

Fig. 13. Regressions (left) and correlations (right) between the sea surface temperature anomalies (annual cycle removed) and the temperature anomalies in upper $300 \mathrm{~m}$. Top row is BlueMargin (strong El Niño) and bottom is BlueGyre (weak El Niño). The similarity between the two analyses suggest that the connection between subsurface and surface temperatures cannot explain the differences between the simulations. The temperature responses in the eastern Pacific between $40 \mathrm{~m}$ and $80 \mathrm{~m}$ are weaker in the with weaker El Niño, the opposite of what would be expected if a larger subsurface temperature perturbation was needed to drive a given SST perturbation.

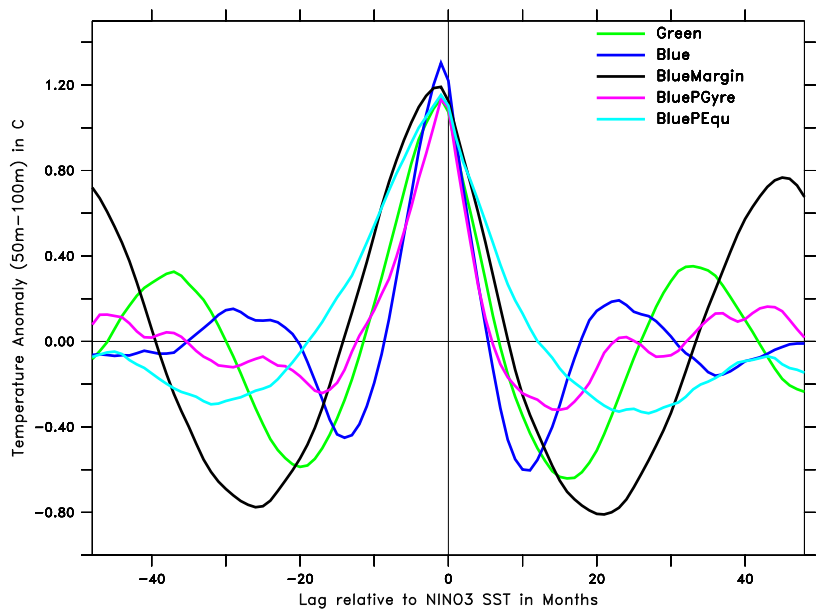

Fig. 14. Time lagged regressions of subsurface temperature anomaly $(50-100 \mathrm{~m})$ in NINO3 region relative to the NINO3 SST anomaly for the five models. Negative lag means that the subsurface leads the surface.

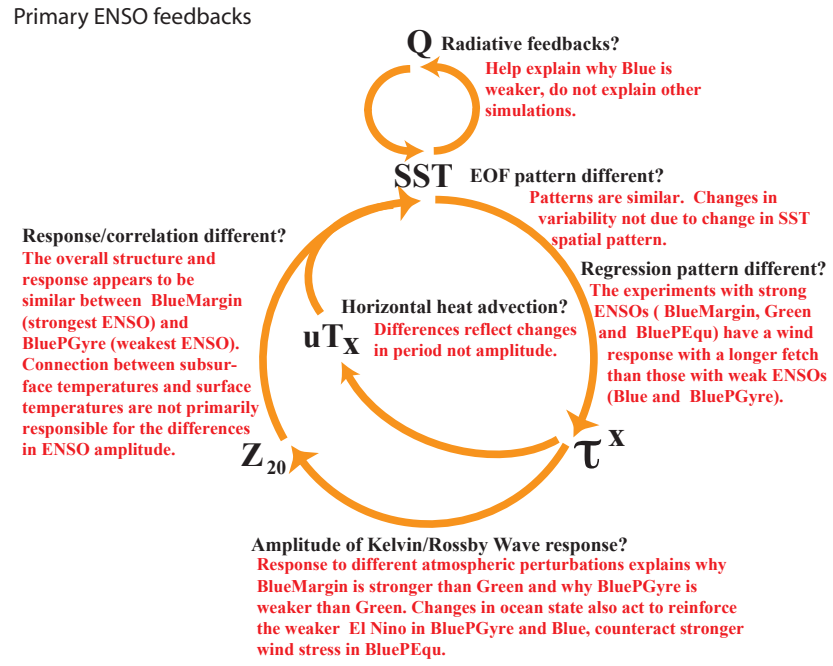

Fig. 15. Cartoon depicting the major feedback loops in the ENSO system with summary of results and discussion. 
atmospheric circulations, the focus tends to be on the Walker circulation. This study suggests that more attention be turned towards variations in the Hadley circulation. As discussed in Wittenberg et al. (2006) the pattern of wind stress response to changes in NINO3 SSTs tends to be focussed between $180 \mathrm{~W}$ and $160 \mathrm{~W}$ in reanalyses and in the GFDL atmosphere-only runs but is shifted westward by about 20 degrees in the GFDL coupled models. Our results suggest that this shift may be related to the stronger Hadley cell seen in the coupled model. We hypothesize that a strengthened Hadley cell tends to pin the convection over Indonesia.

Our results suggest new mechanisms by which the character of ENSO could change on interdecadal time scales. Polovina et al. (2008) note that there are trends in the SeaWiFS chlorophyll dataset, suggesting that the very clear regions are expanding (the same regions implicated earlier in the maintenance of the Pacific cold tongue). Interestingly, the regions that appear to have the largest sensitivity to perturbations, and the largest resulting impact on the climate system, are these near-oligotrophic regions.

The importance of these regions raises another area of research in that less effort has been placed on understanding their optical properties. A particular issue is the role of colored dissolved organic matter, which some investigators suggest is the dominant absorber in many regions (Siegel et al., 2005) and whose concentration varies significantly between different oligotrophic regions. Another issue is the representation of the deep chlorophyll maximum, which is parameterized in formulations such as (Morel and Antoine, 1994) used in previous versions of the GFDL coupled model (Gnanadesikan et al., 2006) but will be explicitly simulated in future versions of the Earth System Model. Our work supports better validation of current parameterizations in such regions and the development of new parameterizations where necessary.

The pathway for the changes in variability seen in our experiments need not be limited to ocean color and shortwave penetration. Any phenomenon that results in a large enough perturbation in vertical heat transport in the regions discussed could be a viable candidate. Unrealistic ENSO variability could be due to poor estimation of off-equatorial shortwave penetration, off-equatorial mixing just below the mixed layer or both. Given that our changes in ocean color map onto some of the key biases in many coupled climate models (changing the temperature of the equatorial cold tongue, enhancing the double intertropical convergence zone) these results suggest that more attention be paid to potential biases in mixing in the tropical upper ocean.

Acknowledgements. The authors would like to thank A. Adcroft, R. Hallberg, J. Dunne, M. Harrison, A. Rosati, S. P. Xie, G. van Oldenborgh and $\mathrm{G}$. Vecchi for valuable suggestions and discussions. W. G. A was supported by NASA grant NNX07AL801G and the NOAA's Geophysical Fluid Dynamics Laboratory through the AOS program at Princeton University.
Edited by: D. Webb

\section{References}

Anderson, W. G., Gnanadesikan, A., Hallberg, R., Dunne, J., and Samuels, B. L.: Impact of ocean color on the maintenance of the Pacific Cold Tongue, Geophys. Res. Lett., 34(11), L11609, doi:10.1029/2007GL030100, 2007.

Ballabrera-Poy, J., Murtugudde, R., Zhang, R. H., and Busalacchi, A. J.: Coupled ocean-atmosphere response to seasonal modulation of ocean color: Impact on interannual climate simulations in the tropical pacific, J. Climate, 20, 353-374, 2007.

Bjerknes, J.: Atmospheric teleconnections from the equatorial pacific, Mon. Weather Rev., 97, 163-172, 1969.

Burgers, G. and van Oldenborgh, G. J.: On the Impact of Local Feedbacks in the Central Pacific on the ENSO cycle, J. Climate, 16, 2396-2407, 2003.

Conkright, M. E., Locarnini, R. A., Garcia, H. E., O’Brien, T. D., Boyer, T. P., Stephens, C., and Antonov, J. I.: World Ocean Atlas 2001: Objective Analyses, Data statistics and Figures, CDRom Documentation, National Oceanographic Data Center, Silver Spring, MD, USA, 17 pp., 2002.

Davey, M. K., Huddleson, M., Sperber, K., et al.: Stoic: a study of coupled model climatology and variability in tropical ocean regions, Clim. Dynam., 18, 403-420, 2000.

Delworth, T. L.,Rosati, A., Broccoli, J. B., et al.: GFDL's CM2 global coupled climate models:part 1 . formulation and simulation characteristics, J. Climate, 19, 645-674, 2006.

Fedorov, A. V., Dekens, P. S., McCarthy, M., Ravelo, A. C., deMenocal, P. B., Barreiro, M., Pacanowski, R. C., and Philander, S. G.: The Pliocene Paradox (Mechanisms for a Permanent El Niño), Science, 312, 1485-1489, 2006.

Gnanadesikan, A. and Anderson, W. G.: Ocean water clarity and the ocean general circulation in a coupled climate model, J. Phys. Oceanogr., 39(2), 314-332., 2009.

Gnanadesikan, A., Dunne, J. P., Key, R. M., Matsumoto, K., Sarmiento, J. L., Slater, R. D., and Swathi, P. S.: Oceanic ventilation and biogeochemical cycling: Understanding the physical mechanisms that produce realistic distributions of tracers and productivity, Global Biogeochem. Cy., 18, GB4010, doi:10.1029/2003GB002097, 2004.

Gnanadesikan, A., Dixon, K. W., Griffies, S. M., et al.: GFDL's CM2 global coupled climate models-part 2: The baseline ocean simulation, J. Climate, 19, 675-697, 2006.

Guilyardi, E.: El Niño - mean state - seasonal cycle interactions in a multi-model ensemble, Climate Dynam., 26, 329D348, 2006.

Hallberg, R.: The suitability of large-scale ocean models for adapting parameterizations of boundary mixing and a description of a refined bulk mixed layer model, Proceedings of the 2003 Aha Hulikoa Hawaiian Winter Workshop, 187-203, 2003.

Hallberg, R.: A thermobaric instability of lagrangian vertical coordinate ocean models, Ocean Model., 8, 279-300, 2005.

Jerlov, N. G.: Marine Optics, Elsevier Oceanograhy Series, 14, 231 pp., 1976.

Lengaigne, M., Menkes, C., Aumont, O., et al.: Influence of the biology on the tropical Pacific climate in a coupled general circulation model, Clim. Dynam.,vol. 28, no5 , doi:10.1007/s00382006-0200-2, 2007. 
Lewis, M. R., Carr, M. E., Feldman, G. C., Esaias, W., and McClain, C.: Influence of penetrating solar radiationon the heat budget of the equatorial Pacific ocean, Nature, 347, 543-545, 1990.

Manizza, M., Quere, C. L., Watson, A., and Buitenhuis, E. T.: Biooptical feedbacks amoung phytoplankton, upper ocean physics and sea-ice in a global model, Geophys. Res. Lett., 32, L05603, doi:10.1029/2004GL020778, 2005.

Martin, P. J.: Simulation of the mixed layer at OWS November and Papa with several models, J. Geophys. Res., 90, 903-916, 1985.

Marzeion, B., Timmerman, A., Murtugudde, R., and Jin, F.: Biophysical feedbacks in the tropical Pacific, J. Climate, 18, 58-70, 2005.

McClain, C. R., Feldman, G. C., and Hooker, S. B.: An overview of the SeaWiFS project and strategies for producing a climate research quality global ocean bio-optical time series, Deep-Sea Res. Pt. II, 51, 5-42, 2004.

Morel, A.: Optical modeling of the upper ocean in relation to its biogenous matter content (case-i waters), J. Geophys. Res., 93, 10749-10768, 1988.

Morel A. and Antoine, D.: Heating rate within the upper ocean in relation to its bio-optical state, J. Phys. Oceanogr., 24, 1652$1665,1994$.

Murtugudde, R., Beauchamp, J., McClain, C. R., Lewis, M., and Busalacchi, A.: Effects of penetrative radiation on the upper tropical ocean circulation, J. Climate, 15, 470-486, 2002.

Nakamoto, S., Kumar, S. P., Oberhuber, J. M., Ishizaka, J., Muneyama, K., and Frouin, R.: Response of the equatorial pacific to chlorophyll pigment in a mixed layer isopycnal ocean general circulation model, Geophys. Res. Lett., 28, 2021-2024, 2001.

Paytan, A. and Griffith, E. M.: Marine barite-recorder of variations in ocean export productivity, Deep-Sea Res. Pt. II, 54, 687-705, doi:10.1016/j.dsr2.2007.01.007, 2007.

Philip, S. and G.J. van Oldenborgh, Shifts in ENSO coupling processes under global warming, Geophys. Res. Lett., 33, L11704, doi:10.1029/2006GL026196, 2006.

Picaut, J., Ioulalen, M., Menkes, C., Delcroix, T., and McPhaden, M. J.: Mechanism of the Zonal Displacement of the Pacific warm pool: implications for ENSO, Science, 274, 1486-1489, 1996.

Polovina, J. J., Howell, E. A., and Abecassis, M.: Ocean's least productive waters are expanding, Geophys. Res. Lett., 35, L03618, doi:10.1029/2007GL031745, 2008.

Reichler, T. and Kim, J.: How well do coupled climate models simulate today's climate?, B. Am. Meteorol. Soc., 89, 303-311, 2008.
Rosati, A. and Miyakoda, K.: A general circulation model for upper ocean simulation, J. Phys. Oceanogr., 18, 1601-1626, 1988.

Schneider, E. and Zhu, Z.: Sensitivity of the simulated annual cycle of sea surface temperature in the equatorial pacific to sunlight parameterization, J. Climate, 11, 1932-1950, 1998.

Shell, K. M., Nakamoto, S., and Somerville, R. C.: Atmospheric response to solar radiation absorbed by phytoplankton, J. Geophys. Res., 108, 1-8, 2003.

Siegel, D. A., Bidgare, R. R., and Zhou, Y.: Solar radiation, phytoplankton pigments and the radiant heating of the equatorial pacific warm pool, J. Geophys. Res., 100, 4885-4891, 1995.

Siegel, D. A., Mariotorena, S., Nelson, N. B., and Behrenfeld, M. J.: Independence and interdependencies among global ocean color properties: Reassessing the bio-optical assumption, J. Geophys. Res., 110, C07011, doi:10.1029/2004JC002527, 2005.

Song, Q., Vecchi, G. A., and Rosati, A.: The role of the Indonesian throughflow in the Indo-Pacific climate variability in the GFDL coupled climate model, J. Climate, 20, 2895-2916, 2007.

Stramska, M. and Dickey, T. D.: Phytoplankton bloom and the vertical thermal structure of the upper ocean, J. Mar. Res., 51, 819842, 1993.

Sweeney, C., Gnanadesikan, A., Griffies, S., Harrison, M., Rosati, A., and Samuels, B.: Impacts of shortwave penatration depth on large-scale ocean circulation heat transport, J. Phys. Oceanogr., 35, 1103-1119, 2005.

Timmerman, A. and Jin, F.: Phytoplankton influences on tropical climate, Geophys. Res. Lett., 39(23), 2104, doi:10.1029/2002GL15434, 2002.

van Oldenborgh, G. J., Philip, S. Y., and Collins, M.: El Niño in a changin climate: a multi-model study, Ocean Sci., 1, 81-95, 2005 , http://www.ocean-sci.net/1/81/2005/.

Wetzel, P. J., Maier-Reimer, E., Motzet, M., Jungclaus, J., Keenlyside, N., and Latif, M.: Effects of ocean biology on the penetrative radiation in a coupled climate model, J. Climate, 19, 39733987, 2006.

Wittenberg, A. T.: ENSO Response to Altered Climates, Ph.D. thesis, Princeton University, USA, 475 pp., 2002.

Wittenberg, A. T., Rosati, A., Lau, N. G., and Ploshay, J. J.: GFDL's CM2 Global coupled climate models, Part III: Tropical Pacific Climate and ENSO, J. Climate, 19, 698-722, 2006. 